\title{
Cooperação para inovação em empresas de saneamento básico brasileiras o odadsentradar
} Cooperation for innovation in Brazilian basic sanitation companies. $\begin{gathered}\text { Dota de aprovacăo: } \\ 12 / 04 / 2019\end{gathered}$

\section{Resumo}

O interesse e envolvimento da sociedade, a relevância econômica do setor e a expectativa de contribuição para a teoria sobre cooperação para inovação explicam a importância da pesquisa. A pesquisa respondeu à pergunta: "quais são os principais arranjos cooperativos identificados por parte das empresas do setor de saneamento básico brasileiro?" O objetivo geral desta pesquisa é identificar os principais arranjos cooperativos para o setor de saneamento básico brasileiro. Foi realizada uma pesquisa exploratória, com a realização de estudos de caso múltiplos, de abordagem qualitativa, com a participação de cinco empresas do setor. As participantes encontram-se listadas no Ranking 1000 da revista Valor Econômico. Os dados foram levantados por meio de pesquisa bibliográfica, pesquisa documental e questionário. Como resultados desta pesquisa destacam-se: a caracterização do aprofundamento da discussão teórica recente relacionada à temática de cooperação para inovação nas empresas e a identificação das principais relações entre os atores envolvendo arranjos cooperativos de inovação do setor de saneamento brasileiro, principalmente fornecedores e universidades, apontados como relações de alta importância.

Palavras-chave: Inovação. Cooperação. Saneamento Básico.

\section{Abstract}

The interest and involvement of society, the economic relevance of the sector and the expectation of contribution to the theory about cooperation for innovation explain the importance of research. The survey answered the question: What are the main cooperative arrangements identified by companies in the Brazilian basic sanitation sector? The general objective of this research is to identify the main cooperative arrangements for the Brazilian basic sanitation sector. An exploratory research was carried out, with the accomplishment of a multiple case study, of qualitative approach, with the participation of five companies of the sector. Participants are listed in Ranking 1000 of the economic value magazine. The data were collected through bibliographic research, documentary research and questionnaire. The results of this research are: the characterization of the deepening of the recent theoretical discussion related to the topic of cooperation for innovation in companies and the identification of the main relations between the actors involving cooperative arrangements of innovation of the Brazilian sanitation sector, mainly (suppliers and universities) Pointed out as relations of high importance.

Keywords: Innovation. Cooperation. Basic Sanitation

\footnotetext{
${ }^{1}$ Escola SENAI Suíço-Brasileira Paulo Ernesto Tolle - São Paulo - São Paulo - Brasil.

${ }^{2}$ Pontifícia Universidade Católica de São Paulo - São Paulo - São Paulo - Brasil.

* Autor correspondente: marcusvendittiasabesp.com.br.
} 


\section{INTRODUÇÃO}

A inovação é definida como a aplicação e implantação comercial de novos conhecimentos e ideias (MCGUIRK; LENIHAN; HART, 2015, p. 966; BARBOZA; FONSECA; RAMALHEIRO, 2015, p. 332). A palavra inovação se destaca no vocabulário empresarial, de modo geral, nas últimas décadas. Não se restringindo apenas aos muros das empresas, envolve governos, universidades e agentes econômicos. Os desafios apresentados em nosso tempo, novos hábitos e comportamentos, por exemplo, solicitam uma orientação para o novo. Nas empresas de uma forma geral, a inovação desempenha um papel importante na competitividade e na sobrevivência. A sua relevância não é exclusiva das grandes organizações ou de empresários individuais. Igualmente, não se restringe às empresas com fins lucrativos (O'SULLIVAN; DOOLEY, 2009, p. 4).

O saneamento básico no Brasil apresenta novos e antigos desafios representados pela universalização no acesso aos serviços de distribuição de água e coleta de esgoto, o reúso dos recursos hídricos, a redução de perdas e a obtenção de financiamento para projetos do setor. Nesse contexto espera-se que o setor apresente uma atitude inovadora objetivando colher benefícios.

O saneamento precisa de inovação, e por que não a inovação não precise do saneamento, com um atrativo rol de oportunidades e problemas a serem solucionados. Para inovar com sucesso, a empresa combinará diferentes atividades de inovação. Além do seu próprio P\&D (Pesquisa e Desenvolvimento), as empresas geralmente estão envolvidas na aquisição de conhecimento no mercado de tecnologia. As empresas que se dedicam apenas a uma única atividade de inovação, seja ela de atividades internas de P\&D ou externas, introduzem menos produtos novos ou substancialmente melhorados em comparação com empresas que as combinam (CASSIMAN; VEUGELERS, 2006, P. 68). As empresas inovadoras em produtos e processos estão mais ligadas às instituições de pesquisa. Já empresas que adaptam tecnologia o fazem a partir das empresas que se relacionam comercialmente (TIGRE, 2006, p. 133). A empresa deve decidir entre comprar ou produzir a tecnologia de que necessita ou estabelecer uma relação complementar entre compra e inovação (ANDREASSI, 2005, p.2-3). Sendo assim, este artigo tem por objetivo identificar os principais arranjos cooperativos para o setor de saneamento básico brasileiro, no entendimento de que a inovação necessita do envolvimento de mais de um ator na busca de soluções construídas de forma compartilhada. De forma secundária tem-se como objetivo apresentar a discussão teórica recente relacionada à temática de cooperação para inovação nas empresas. Em conjunto, o atingimento dos objetivos propostos proporciona responder: "quais são os principais arranjos cooperativos identificados por parte das empresas do setor de saneamento básico brasileiro?".

Justifica-se a pesquisa na expectativa de contribuição para a teoria sobre cooperação de inovação no setor de saneamento, buscando-se relacionar os desafios oriundos da cadeia produtiva às oportunidades exploradas pela cadeia inovativa e pela relevância econômica do setor e a sua importância para a sociedade, como veremos adiante. Acredita-se ainda que a pesquisa possa contribuir para a teoria, visto que o levantamento bibliográfico acerca do assunto mostrou a escassez de material, incluindo a não participação do setor de saneamento na PINTEC (Pesquisa de Inovação do IBGE), que por si só já é uma enorme lacuna, visto que a referida pesquisa já acontece no Brasil desde 2000 e se tornou referência para as pesquisas realizadas na área de inovação.

Segundo Braga (2007), uma pesquisa exploratória como essa não tem objetivo de levantar hipóteses, mas somente de procurar padrões. Mesmo assim, entende-se que a hipótese de identificar uma forte participação de fornecedo- 
res e universidades na composição dos arranjos cooperativos em conjunto com as empresas de saneamento em detrimento de outras partes interessadas seja testada.

No contexto da pesquisa, tem-se que o saneamento ambiental é um conjunto de serviços que compreende abastecimento de água, esgotamento sanitário, drenagem pluvial, limpeza urbana e manejo de resíduos sólidos urbanos (BNDES, 2015 p. 155). A cadeia produtiva do setor compreende as atividades de conservação de recursos hídricos, captação de água, tratamento de água, adução, reservação, uso, coleta de esgoto, tratamento de esgoto e disposição de efluentes e resíduos sólidos. Já a cadeia de inovação envolve a participação de fornecedores de equipamentos e materiais, projetistas e institutos de ciência e tecnologia, outras empresas de saneamento, fornecedores de serviços operacionais, organizações não governamentais e órgãos reguladores (SABESP, 2009).

O setor de saneamento brasileiro é composto por 28 empresas de âmbito estadual, 6 de âmbito regional (atendem mais de um município) e 1408 municipais, totalizando 1442 prestadores de serviços no setor. Quanto à natureza jurídica, 902 empresas fazem parte da administração direta, 413 são autarquias, 31 são sociedades de economia mista, 5 são empresas públicas, 89 são empresas privadas e 2 são organizações sociais (SNIS, 2015, p. 9).

Quanto à relevância econômica do setor, pode-se afirmar que a expansão do setor de saneamento traz aumento de oportunidades para segmentos da indústria que vendem produtos e prestam serviços para os segmentos de água e esgoto. Para cada R\$ 1 bilhão investido no setor de saneamento, são gerados $\mathrm{R} \$ 3,1$ bilhões de acréscimo no valor bruto da produção total das indústrias fornecedoras para o setor. São gerados 58,2 mil empregos, com $\mathrm{R} \$ 545$ milhões de crescimento da massa salarial e $\mathrm{R} \$ 216$ milhões de aumento da arrecadação de impostos (CNI, 2014 p.13).

Muitas vezes o bom desempenho econômico das empresas vem da parceria encontrada nas universidades ou institutos de pesquisa, na utilização de recursos humanos qualificados, assessoria técnica, com acesso aos laboratórios, permitindo o acompanhamento da evolução científica e tecnológica (MARTIN; TORKOMIAN, 2001, p. 6). Segundo pesquisa realizada na China, entre 1993 e 1995, com a participação de 3.346 empresas, $74 \%$ das empresas afirmam que realizaram algum tipo de inovação nesse período com relacionamentos de cooperação com universidades e institutos de pesquisa (ZHANG EXU, 1998, p. 1).

O conhecimento novo pode ser gerado pela empresa inovadora no curso de suas atividades ou adquirido externamente por meio de vários canais. $\mathrm{O}$ uso de conhecimento novo ou a combinação do conhecimento existente requer esforços inovadores que podem ser distinguidos das rotinas padronizadas (OCDE, 2005, p. 43). Segundo o IBGE (2011, p. 23), as empresas podem utilizar novos conhecimentos produzidos em suas áreas de $P \& D$ ou de conhecimentos incorporados, principalmente por meio de aquisição tecnológica. Ainda segundo essa publicação, a inovação nas empresas está diretamente ligada à sua capacidade de absorver e combinar informações.

O artigo está organizado em capítulos, conforme segue: Metodologia, Resultados, Discussão e Conclusão.

\section{METODOLOGIA}

Em relação à natureza, entende-se que se trata de pesquisa básica por buscar conhecimentos novos por meio de uma pesquisa exploratória, proporcionando maior familiaridade com o problema, tornando-o mais explícito, consolidan- 
do a reunião de dados, informações, padrões e ideias sobre o problema de pesquisa (GIL, 2008). Uma vez definida a natureza da pesquisa, o próximo passo é definir a melhor abordagem. A presente pesquisa adotou uma abordagem qualitativa, que se mostrou mais adequada à realidade do estudo do fenômeno (MINAYO; SANCHES, 1993, p. 247).

Sendo assim, desenvolveu-se um estudo de caso múltiplo acerca das cinco empresas respondentes, adotando fontes de coleta secundárias e primárias. Utilizando o protocolo proposto por Yin (2001, p.34-35), efetuou-se a análise dos dados coletados buscando uma visão abrangente dos cinco casos. O autor ressalta dois aspectos importantes a serem respeitados. 0 primeiro trata da forma como a amostra é selecionada, considerando o interesse do caso estudado e sua relação com as variáveis do fenômeno. Além do mais, deve ser considerado também o número de casos e a relevância dos mesmos.

$\mathrm{Na}$ etapa da coleta de dados secundária, foi planejada e executada uma pesquisa bibliográfica, orientada pelos portais de periódico Google Acadêmico e Scielo, utilizando-se as seguintes palavras-chave: Inovação, Cooperação para Inovação e Cooperação para Inovação em Saneamento. As bases de dados foram pesquisadas em busca de artigos publicados desde 2006 até 2016. Ainda em relação à coleta de fontes secundárias, procedeu-se à análise dos resultados da PINTEC 2014, com foco no setor de utilidades (Eletricidade e Gás), pela similaridade ao setor estudado.

No setor foram identificadas 8 empresas como sendo potenciais inovadoras e 25 sem identificação de potencial inovador, em um extrato de 63 (PINTEC, 2014, p.30) sendo considerada a amostra formada pelas empresas que elencadas no Ranking 1000 da Revista Valor, estratificadas pelo setor de saneamento básico. A decisão pela escolha vem do fato de as empresas listadas serem as maiores empresas do setor. A receita operacional do setor de saneamento totaliza $\mathrm{R} \$ 47,3$ bilhões, sendo que as 21 empresas listadas no Ranking 1000 representam $1,45 \%$ do total de empresas do setor, que contribuem com $\mathrm{R} \$ 41,4$ bilhões, representando $87,52 \%$ do montante de receita. A escolha do periódico foi por conveniência do autor.

A participação na pesquisa como respondentes indicados se deu pelos gerentes de $P \& D$ das empresas do setor de saneamento em função do know-how que estes possuem em relação à atividade de inovação no setor. Por meio dos contatos realizados com as 21 empresas da amostra obteve-se a identificação de 12 contatos (57,14\%). Os gestores identificados foram contatados via e-mail com encaminhamento do link para participação na pesquisa e em anexo o formulário em arquivo do Word.

Quanto ao momento em que os dados são coletados, esta pesquisa é considerada como sendo de corte-transversal, com a coleta de dados ocorrendo em um só momento, após a conclusão de um período de três anos (de janeiro de 2014 a dezembro de 2016). O período alongado é fundamental no estudo deste fenômeno, visto que o investimento feito e as ações tomadas no presente, por exemplo, nem sempre refletem em resultados imediatos.

O planejamento da coleta de fontes primárias sucedeu com a elaboração de questionário com perguntas fechadas e uma pergunta aberta. A elaboração da questão aberta ocorreu após a análise dos resultados das questões fechadas, buscando o aprofundamento do fenômeno. 0 questionário aplicado foi adaptado da Pintec (IBGE, 2014), considerando-se o contexto em que a inovação ocorre e a cooperação para inovação. Com o retorno dos formulários respondidos, procederam-se à sumarização, análise e 
interpretação dos resultados com a finalidade de respondermos as questões problematizadas.

Os dados foram analisados na busca de padrões entre as empresas do setor de saneamento básico brasileiro a serem identificados por meio de estatística descritiva. Os dados foram analisados com dois vieses. O primeiro pela comparação entre as empresas participantes, quando possível, buscando identificar um padrão entre as informações coletadas. A segunda por meio de referencial comparativo, a PINTEC 2014 (IBGE). $O$ referencial comparativo devido à similaridade com o setor estudado será o setor de utilidades formado pelos setores de Eletricidade e Gás.

\section{RESULTADOS}

As bases de dados foram pesquisadas em busca de artigos publicados desde 2006 até 2016, englobando os últimos dez anos de pesquisas sobre o tema. Após seleção e avaliação, foram relacionados e fichados 281 artigos com potencial de utilização na pesquisa.

Uma relação foi confeccionada em planilha Excel organizada pelos seguintes dados em colunas: Autor principal, Ano da publicação, Referência ABNT, Periódico e classificação Qualis-Periódicos. Por meio do cruzamento de referências dos artigos inicialmente relacionados e da primeira análise de conteúdo foi possível selecionar 110 artigos que foram igualmente relacionados e fichados, sendo que $45(40,9 \%)$ artigos foram publicados em periódicos internacionais.

Em uma segunda etapa com o objetivo específico caracterizar as empresas do setor de saneamento básico no Brasil, procedeu-se a uma pesquisa documental recorrendo à consulta dos documentos das empresas disponíveis em seus sites, das associações setoriais e órgãos reguladores, que contribuam para o aprofundamento do entendimento do fenômeno. Foram coletados os Relatórios de Demonstrações Financeiras, Relatórios de Sustentabilidades das empresas pesquisadas e relatórios de diagnósticos, caracterização e desempenho setorial. Foram coletados 33 documentos.

Ainda em relação à coleta de fontes secundárias, procedeu-se a análise dos resultados da PINTEC 2014, com foco no setor de utilidades (Eletricidade e Gás), pela similaridade ao setor estudado. No setor foram identificadas 8 empresas como sendo potenciais inovadoras e 25 sem identificação de potencial inovador, em um extrato de 63 (PINTEC, 2014, p.30). A preocupação inicial era que o aspecto quantitativo do estudo da pesquisa do IBGE trouxesse uma realidade numérica muito superior, que não se mostrou ser verdade.

Foram enviados 12 e-mails aos respondentes identificados, sendo que $2(16,8 \%)$ declinaram de responder, $5(41,6 \%)$ não se posicionaram e 5 $(41,6 \%)$ responderam.

A mensuração das principais assertivas do questionário, conforme quadro analítico da pesquisa, é representado por um score de 4 níveis (alta, média, baixa e ausência), que nos gráficos ilustrados a seguir correspondem no eixo vertical a alta (3), média (2), baixa (1) e ausência (0). Para comparação com os dados da Pintec, assumiu-se a metodologia da mesma e aplicou-se tratamento percentual à escala (0-100) adotando o 3 da escala da pesquisa como $100 \%$. Para a apresentação dos dados sumarizados, utilizou-se a média dos resultados entre as cinco empresas (Aegea, Sabesp, Embasa, Sanepar e Copasa).

Indagados: "Entre 2014 e 2016, qual foi a intensidade com que a empresa esteve envolvida em arranjos cooperativos com outra(s) organização(ões) com vistas a desenvolver atividades inovativas?", os respondentes de 4 das 5 empresas afirmaram uma intensidade média no desenvolvimento desses arranjos e 1 não se manifestou. 


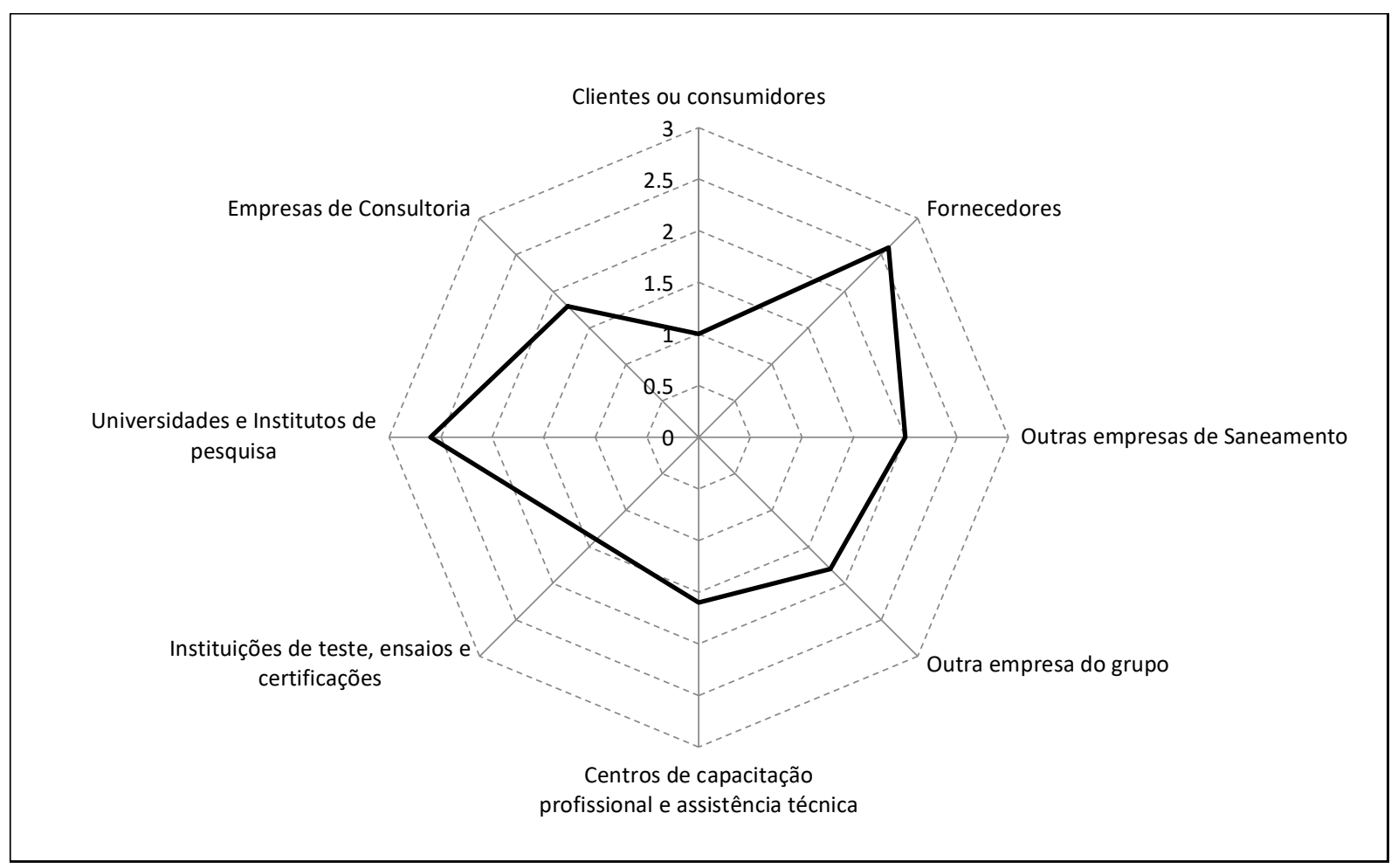

Figura 1 - Importância dada ao parceiro em atividades de cooperação.

Fonte: dados da pesquisa

A visão do setor (Fig. 1) demonstra uma maior importância à parceria em atividades de cooperação envolvendo fornecedores e universidades com um resultado de 2,60 pontos de intensidade. Beuren, Floriani e Hein (2014), em sua pesquisa, indicam como um bom modelo de gestão de inovação aquele que conte com relações fortes de parceria com fornecedores e universidades. Esses parceiros são seguidos por outras empresas de saneamento $(2,00)$, outra empresa do grupo e empresas de consultoria $(1,80)$, centros de capacitação profissional e assistência técnica $(1,60)$, instituições de testes, ensaios e certificações $(1,40)$ e clientes ou consumidores $(1,00)$. Desse resultado, o que mais se destaca é a baixa importância atribuída a clientes e consumidores pelos respondentes. Existe um contraste com os trabalhos de Cappelli, Czarnitzki, Kraft (2014) e Zeng (2009), que apontam uma grande relevância para estes parceiros. Na Fig. 2 é possível visualizar os resultados sumarizados quanto à importância dada pelas empresas pesquisadas ao parceiro em atividades de cooperação.

A mensuração das principais assertivas do questionário utilizado é representada por um score de 4 níveis (alta, média, baixa e ausência), que nos gráficos ilustrados a seguir correspondem no eixo vertical a alta (3), média (2), baixa (1) e ausência (0). Para comparação com os dados da Pintec, assumiu-se a metodologia da mesma e aplicou-se tratamento percentual à escala (0-100) adotando o 3 da escala da pesquisa como $100 \%$. Para a apresentação dos dados sumarizados, utilizou-se a média dos resultados entre as cinco empresas. 


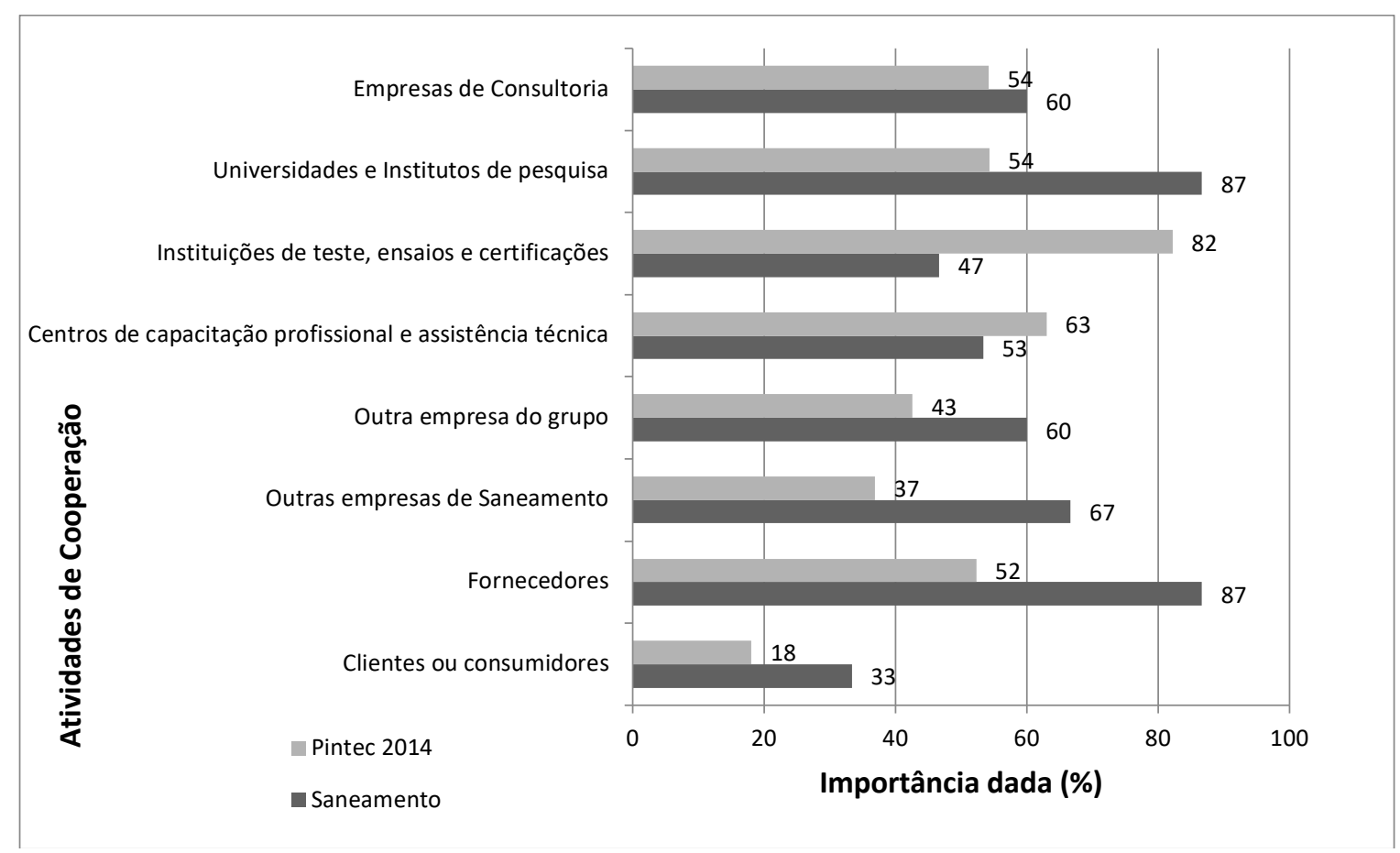

Figura 2 - Importância dada ao parceiro em atividades de cooperação Fonte: dados da pesquisa

Para a Aegea, única empresa privada da amostra, percebe-se uma divergência quanto ao resultado do setor acima descrito. O mesmo aponta para uma importância alta atribuída à parceria desenvolvida com outra empresa do grupo e empresas de consultoria. Para o grupo formado pelos fornecedores, universidades, institutos de pesquisa, outras empresas de saneamento, centros de capacitação profissional e assistência técnica, foi mensurada uma intensidade média a esses parceiros. Uma intensidade baixa foi dada às instituições de testes, ensaios e certificações. Não se considerou relevante a ação de clientes ou consumidores.

Para a Sabesp, uma importância alta foi dada aos parceiros em atividades de cooperação para universidades, institutos de pesquisa e clientes ou consumidores. Uma média importância foi dada a fornecedores, centros de capacitação profissional, assistência técnica, instituições de testes, ensaios e certificações. A outras empresas de saneamento foi atribuída baixa importância e ou- tra empresa do grupo e empresas de consultoria não se mostraram relevantes.

Para a Embasa, atribuiu-se alta importância aos fornecedores, outras empresas de saneamento, outra empresa do grupo e empresas de consultoria nas atividades de cooperação seguida por universidades com média intensidade e por clientes ou consumidores, centros de capacitação profissional, assistência técnica e instituições de testes, ensaios e certificações com baixa intensidade.

A Copasa e Sanepar mais se aproximaram do resultado do setor, atribuindo alta intensidade às relações de cooperação com universidade, institutos de pesquisa e fornecedores. Para a Copasa, outras empresas de saneamento, instituições de testes, ensaios e certificações atribuiu-se média intensidade. Em relação à outra empresa do grupo, empresas de consultoria, centros de capacitação profissional e assistência técnica mensuraram essas relações como sendo de baixa 
intensidade e como não relevantes à parceria desenvolvida com clientes ou consumidores.

Para Sanepar atribuiu-se média intensidade às atividades de cooperação envolvendo outras Empresas de Saneamento, outra empresa do grupo, empresas de consultoria e centros de capacitação profissional e assistência técnica. Já para instituições de testes, ensaios e certificações e clientes ou consumidores, foi atribuída uma baixa intensidade a essas atividades.

Perguntamos às empresas: "Qual foi o principal parceiro em atividades de cooperação?”. Apenas 2 empresas (40\%) responderam à questão indicando a principal fonte como sendo clientes, divergindo da resposta obtida na questão anterior. Em relação à localização do principal parceiro em atividades de cooperação, $40 \%$ das empresas identificaram como sendo no exterior e $60 \%$ no Brasil.

No sentido de aprofundamento no estudo do fenômeno, perguntou-se de forma aberta aos respondentes: “Na sua percepção, como se caracterizam as relações da empresa com as universidades na realização de projetos de inovação conjuntos ou na cooperação para a inovação em geral?".

Para a representante da Embasa, esse ainda é um processo de "inovação", percebendo que nos últimos anos as universidades passaram a entender que o conhecimento produzido nas academias precisa estar à disposição da sociedade e que para tal a indústria precisa transformar esse conhecimento em produto ou serviço para o bem comum. Assim como as empresas passaram a se utilizar da academia para embasar a tomada de decisão de mudança, melhoria e inovação dos seus processos, produtos e serviços. Essa consciência facilita a relação, imprimindo à relação empresa $x$ universidade um compasso mais coerente, começando ambas a caminharem, ainda que lentamente, num ritmo mais igual. Ainda assim, a contribuição de ambas nos projetos de inovação é pontual e esporádico.

No caso da Sanepar, o respondente indicou que a relação com as universidades está ligada diretamente ao tema de pesquisa. Que em seu caso trabalha em rede estruturada no Paraná com 20 universidades entre instituições estaduais e federais e 13 ações de cooperação com universidades internacionais. A cooperação acontece de maneira formal, com a celebração de acordos de cooperação técnica ou de maneira informal de acordo com o objeto por meio de identificação trazida por pesquisadores. São resultados da cooperação, produtos técnicos, treinamento e workshops. Existe um procedimento normativo para identificação e seleção de novas oportunidades tendo a área de suprimentos como entrada inicial, a área operacional como área meio e como centralizador a área de P\&D.

Para a Sabesp, a parceria com a Fapesp, iniciada em 2009, já rendeu 17 projetos, nove deles concluídos, com investimento de $\mathrm{R} \$ 5,2$ milhões, e outros oito projetos foram aprovados com investimentos previstos de $R \$ 7$ milhões e prazo de execução de 42 meses (SABESP, 2017).

Para o representante da Aegea, a relação é muito boa, mas a burocracia em excesso dificulta este caminho (não viabiliza). Já a Copasa caracteriza essa relação por uma iniciativa de ajuda, porém ainda sem uma clara definição de divulgação de resultados e dependência grande das universidades com as empresas para testarem seus projetos.

\section{DISCUSSÃO}

A inovação vem sendo considerada fator crítico, uma questão de sobrevivência para as empresas mediante um cenário de alta competitividade em seus ambientes, setoriais e de mercado. Não se chega a um ponto comum em relação ao conceito de inovação nos redutos acadêmicos, políticos e 
empresariais. A razão dessa divergência vem dos intensos impactos que as inovações têm ocasionado nas empresas, na economia e na sociedade (PAULA et al., 2015, p. 233; BARBOZA; FONSECA; RAMALHEIRO, 2015, p. 332).

Tidd e Bessant (2015, p. 21-22) propõem um modelo simples com o objetivo de explicar o processo de gerenciamento de inovação por meio de quatro ações: buscando ideias para proporcionar quantidade e variedade; selecionando as melhores oportunidades baseadas em estratégia; implementando por meio de gerenciamento dos recursos e aprendendo por meio de sabedoria acumulada em acertos e erros. Nesse sentido, é importante destacar o papel da área de Pesquisa e Desenvolvimento, a qual possibilita à empresa assimilar e explorar o conhecimento do ambiente, utilizando-se de qualquer tecnologia sofisticada e operando-a com eficiência (ANDREASSI, 2005, pp. 2-3).

As empresas inovam em busca de benefícios, que se traduzem no desenvolvimento (fornecer um nível de novidade, integração junto ao cliente), na competição (evitar superação pelas rivais, evitar perda participação de mercado, evitando a perda de faturamento e poder de defesa da empresa) e na diferenciação (obtenção de vantagem competitiva) (OCDE 2005, p. 43; GAVA; ZILBER, 2014, p. 4; TEZA et al. 2015, p. 61).

Em se tratando da visão econômica, inovação é um processo diretamente relacionado à renovação tecnológica. Nasce do intercâmbio de conhecimento, orientado para o aprendizado organizacional, definindo lideranças estratégicas claras. Há de se considerar a utilização de recursos que a viabilizem. São eles a estrutura e o ambiente, que devem estimular as pessoas a explorar sua criatividade e principalmente compartilhar sua expertise, objetivando à promoção de mudanças e conexões proativas entre a empresa e suas partes interessadas, de modo que possam contribuir para o processo de inovação (CENTURIÓN et al., 2015, p. 27).

Quanto às etapas do processo de inovação, a inovação pode ser entendida como um processo que consiste em várias etapas. Enquanto alguns teóricos veem que esses estágios progridem de forma sequencialmente linear, outros veem a inovação como um processo complexo, com progressões múltiplas, cumulativas e conjuntivas de atividades convergentes, paralelas e divergentes. A visão do primeiro grupo de estágios de inovação foi rotulada como "modelo linear", e a visão do último grupo foi categorizada como "modelo interativo" (GOPALAKRISHNAN; DAMANPOUR, 1997, p. 16).

Pode-se classificar o conceito inovação quanto à natureza: produto, processo, marketing e organizacional; quanto à intensidade: Incremental ou Radical ou quanto à estratégia: inovação aberta e fechada. Pode-se afirmar que inovação é um fenômeno multidimensional que para ser entendido é necessário que seja conceituado por meio de uma tipologia. Seguindo as referências da PINTEC e do Manual de Oslo, da OCDE (Organização de Cooperação e de Desenvolvimento Económico), delimitam-se os tipos de inovação por natureza como sendo de produto, de processo, organizacional e de marketing (BARBOZA; FONSECA; RAMALHEIRO, 2015, p. 333; CENTURIÓN, et al, 2015; PAREDES et al., 2015, p. 142, MATTOS; STOFFEL; TEIXEIRA, 2010, p. 15).

A Inovação de produto é definida pela OCDE (2005, p. 54) como a implantação ou comercialização de um produto com características de desempenho melhoradas de modo a fornecer objetivamente ao consumidor serviços aprimorados ou novos. Do ponto de vista do consumidor, o produto novo cria diferentes vantagens em relação aos produtos anteriores que estavam disponíveis no mercado (BARBOZA; FONSECA; RAMALHEIRO, 2015, p.333). Já para as empresas, eles 
incorporam novas características ou utilidades com potencial de comercialização, atendendo ou utilizando soluções criativas para desenvolvimento de demandas dos mercados consumidores (BEUREN; FLORIANI; HEIN, 2014, p. 5).

As inovações de processo são determinadas pela implantação ou adoção de métodos de produção ou comercialização de produtos novos ou significativamente aprimorados de oferta de serviços ou para manuseio e entrega de produtos. Ela pode envolver mudanças de equipamento, recursos humanos, procedimentos de trabalho ou uma combinação destes (OCDE, 2005, p. 58; IBGE, 2011, p.11), sendo capazes de reduzir os custos e aumentar as margens de lucro (BARBOZA; FONSECA; RAMALHEIRO, 2015, p. 333).

As inovações organizacionais envolvem mudanças na estrutura da empresa, seu gerenciamento, introdução de estratégias distintas, que podem interagir ou não no processo produtivo. A implantação de programas de qualidade ou novos programas estratégicos de gestão são apresentados como inovações organizacionais (BEUREN; FLORIANI; HEIN, 2014, p. 6; OCDE 2005, p. 61). Espera-se como resultado a melhoria do fluxo das atividades organizacionais e de posicionamento de mercado, com perspectivas intra-organizacionais ou inter-organizacionais, estabelecendo novas fronteiras, baseadas com suas estruturas e ou procedimentos (PAREDES, 2015, p.142). Essa busca por resultado envolve a descoberta e a adoção de uma nova forma de criar, capturar, disponibilizar valor para uma empresa ou para o seu cliente (BARBOZA; FONSECA; RAMALHEIRO, 2015, p. 333).

As inovações mercadológicas são diferenciadas pelos ajustes e inovações praticados com foco em comercialização, logística, apresentação do produto, embalagens e demais ações inovadoras que tenham única e exclusivamente a preocupa- ção de oferecer benefícios ao cliente (BEUREN; FLORIANI; HEIN, 2014, p. 6).

Segundo a OCDE (2005, p. 70), as inovações caracterizadas como radicais possuem duas importantes características: pode-se definir essa inovação como uma nova configuração de mercado, pela introdução do inédito, passando pela criação de um produto, processo ou até mesmo um novo mercado e requer um período mais abrangente em relação à análise dos seus impactos. Ela é baseada em desvios significativos relacionados ao design e à concepção do produto, potencialmente abre novas aplicações e novos mercados. Por consequência, requer mudanças significativas nas rotinas organizacionais e nos processos das empresas criadoras (BARBOZA; FONSECA; RAMALHEIRO, 2015, p. 333).

Com a sua implantação, as inovações radicais aumentam o interesse dos mercados consumidores, gerando elevação dos preços, reduzindo os custos ou criando facilidades. Para instigar a geração de inovações radicais esperam-se recompensas por ideias novas e entende-se que ideias oriundas das melhorias incrementais podem ser fontes para as inovações radicais (BEUREN; FLORIANI; HEIN, 2014, p. 164).

As inovações incrementais têm em seu conceito alterações, avanços e ajustes nos bens e serviços produzidos, no processo produtivo, no relacionamento com clientes que possibilitam percepções de melhorias. Esse tipo de inovação é encontrado em empresas estabelecidas, por serem menos arriscadas, exigindo menor quantidade de recursos para sua implementação (BEUREN; FLORIANI; HEIN, 2014, p. 164; BARBOZA; FONSECA; RAMALHEIRO, 2015, p. 333).

A especificidade do setor de saneamento básico e a necessidade de cumprimento de regras e normas exigem certos procedimentos para a implantação de inovações e favorecem as de inovações de caráter incremental, sendo que os ciclos 
de implementação e difusão de inovações normalmente são longos. A dependência de fornecedores, a diversidade de agentes envolvidos e o afastamento relativo das empresas das universidades e centros de pesquisas tornam ainda mais complexa a gestão, implementação e difusão de inovações, principalmente as radicais (BEUREN; FLORIANI; HEIN, 2014, p.168).

Em seus trabalhos, Chesbrough (2003) e Chesbrough, Vanhaverbeke e West (2006) afirmam que as organizações necessitam buscar novas soluções fora de seu domínios para as novas concepções, independentemente dos departamentos de P\&D. Um vocabulário novo relativo à gestão de inovação passa a ser utilizado: colaboração, compra de tecnologia ou licenciamento de processos ou produtos por meio de patentes, originadas externamente à empresa, vindas de outras organizações por meio de relações de colaboração em desenvolvimento conjunto. Sendo assim, descobertas não comercializadas por determinadas empresas podem ter valor em outra. Nesse cenário, o ambiente externo passa a compor elemento importante nas estratégias de inovação. Os departamentos de $P \& D$ não são mais a única fonte de inovação nas organizações. A velocidade de inovar apresenta-se cada vez maior, em meio a um fluxo colaborativo envolvendo o ambiente interno e externo.

O processo de inovação é um processo interativo, realizado com o apoio de inúmeros agentes que possuem distintos tipos de informações e conhecimentos. Esse intercâmbio se dá em vários níveis, entre diversos departamentos de uma mesma empresa, entre empresas e outras organizações (LEMOS, 1999, p.127). Fazer melhorias e adaptar produtos, processos ou serviços não é suficiente para o cenário atual. A inovação deve atender aos diferentes mercados. Nesse sentido, as empresas estão conduzindo suas atividades em pesquisa e desenvolvimento de forma global, aproximando-se do mercado, aumentando o acesso a tecnologias e experiência, construindo parcerias com fornecedores, competidores, universidades e pesquisadores na busca de fontes de inovação que possam levar a empresa ao próximo estágio (SEREIA; STAL; CÂMARA, 2015, p. 655).

Ainda de acordo com os autores, a tendência do avanço das tecnologias e dos altos custos para manter áreas de pesquisa e desenvolvimento faz com que as empresas necessitem formar consórcios para vencer esse desafio. Essas alianças fazem com que as empresas complementem-se em suas competências. Esse tipo de parceria pode ocorrer tanto entre empresas de uma cadeia produtiva como entre concorrentes, no caso dos últimos em busca de soluções tecnológicas básicas.

Nesse contexto, a decisão de cooperar com as universidades não pode ser analisada isoladamente da estratégia global de inovação da empresa. Cooperar com as universidades é complementar a outras atividades de inovação, tais como a realização de $P \& D$, a aquisição de informação pública e a cooperação com outros parceiros. Esses acordos de cooperação são formados sempre que o risco não é um obstáculo importante para a inovação e geralmente servem para compartilhar custos. De acordo com o paradigma da ciência aberta, não se encontram evidências da importância da capacidade de apropriar os retornos da inovação para explicar os acordos de cooperação com as universidades (VEUGELERS; CASSIMAN, 2005, p. 355-379).

A cooperação que ocorre entre empresas e sua cadeia de fornecedores para desenvolver soluções inerentes aos negócios pode ocorrer também entre concorrentes na busca de desenvolvimento de ciência básica em uma fase inicial competitiva. O processo de transferência de tecnologia se dá por meio de contratos de assistência técnica, aquisição de licenças de fabricação e licenças para exploração de marcas registradas 
e aquisição de serviços técnicos e de engenharia (TIGRE, 2006, p.116).

Em continuidade, o surgimento de novas tecnologias vem encurtando os ciclos de vida dos produtos, dos processos subjacentes e aumentando seus custos. A transferência de tecnologia das instituições acadêmicas e científicas transformou-se assim em uma variável estratégica para as empresas no enfrentamento desses desafios. É necessário examinar mais a fundo o papel da transferência informal de tecnologia na universidade, os incentivos de acadêmicos e de cientistas para cooperar com a indústria e no processo, tais como consultores, incubadoras, treinadores e intermediários financeiros. A transferência informal de tecnologia pode ser particularmente importante nas economias emergentes. Tais economias poderão competir melhor em termos de desenvolvimento de tecnologia que não exija laboratórios e equipamentos de alto custo por causa de deficiências em suas infraestruturas e pode ser capaz de alavancar as economias desenvolvidas em termos de avanços tecnológicos que não são patenteáveis (AUDRETSCH; LEHMANN; WRIGHT, 2014, p. 301 -312).

A compra de uma tecnologia superior possibilita o avanço tecnológico em processos ou produtos. Porém, sem o esforço próprio, a adaptação à tecnologia adquirida verifica-se apenas eficiência estática, sem consequente ganho de produtividade. Já a eficiência dinâmica verifica-se quando a transferência de tecnologia é seguida do desenvolvimento e da promoção de inovações incrementais em produtos e processos (TIGRE, 2006, p.116).

Existem canais formais e informais de conhecimento universitário e transferência de tecnologia. Embora a transferência de tecnologia formal envolva tipicamente um contrato legal em uma patente ou em atividades de pesquisa colaborativas, os canais informais de transferência se re- ferem a contatos pessoais e, portanto, à dimensão tácita da transferência de conhecimento. No entanto, a pesquisa é escassa em relação à interação dos mecanismos formais e informais de transferência. Existe uma relação complementar entre os modos de transferência de tecnologia formal e informal: usando ambos, o canal de transferência contribui para um maior desempenho em inovação. A gestão da empresa deve, por conseguinte, esforçar-se por manter relações informais estreitas com as universidades para realizar todo o potencial da transferência de tecnologia formal (GRIMPE; HUSSINGER, 2013, p. 683-700).

A literatura sobre as relações universidade-empresa revela muitas barreiras que impedem a transferência de tecnologia. Um número crescente de organizações intermediárias, tais como Escritórios de Transferência de Tecnologia, Incubadoras Universitárias e Centros de Pesquisa Colaborativa, foram estabelecidos para mitigar tais barreiras. Embora as atividades e efeitos desses intermediários sejam frequentemente estudados, estão faltando entendimentos sobre como essas organizações facilitam a transferência de tecnologia. Esses diferentes tipos de organizações intermediárias abordam a mesma questão fundamental de unir as diferentes lógicas entre academia e indústria de diferentes maneiras. As organizações intermediárias podem reduzir a distância cognitiva, geográfica, organizacional e social nas colaborações entre Universidade e Indústria. As organizações intermediárias abordam diferentes dimensões de proximidade, dependendo da experiência prévia dos atores acadêmicos e industriais e da natureza do conhecimento transferido. Em particular, os Escritórios de Transferência de Tecnologia se concentram mais em melhorar as dimensões cognitivas e organizacionais, enquanto as Incubadoras Universitárias e Centros de Pesquisa Colaborativa tentam reduzir a distância social e geográfica (VILLANI, RASMUSSEN, GRIMALDI, 2017, p. 86-102). 
Em meio ao processo, os transbordamentos devem ser considerados com importantes fontes de inovação. Como resultado direto da estratégia adotada quanto à inovação, é possível identificar o impacto de transbordamento de diferentes fontes de inovação nas vendas. Os transbordamentos de fontes diferentes não têm os mesmos efeitos, enquanto os transbordamentos dos concorrentes importam para a imitação, os clientes e as instituições de pesquisa entregam o conhecimento valioso para vendas com novidades no mercado. Os transbordamentos são externalidades positivas e, portanto, valorizados positivamente pela empresa receptora. Em contraste, uma empresa que enfrenta transbordamentos de saída irá avaliar a externalidade negativamente como a vantagem que vai para os concorrentes no mesmo mercado. Essas avaliações conflitantes não existirão se os transbordamentos vierem de uma fonte externa ao setor. Este é o caso se os transbordamentos derivam de uma instituição de pesquisa e clientes. Esse tipo de informação é usado para a inovação, não para a imitação e essa é a razão para a avaliação incontroversa, efeito dos transbordamentos de $P \& D$ nas vendas realizadas por produtos novos para a empresa (imitação) e novos no mercado (inovação). Acontece que os transbordamentos de rivais levam a mais imitação, enquanto a entrada de clientes e instituições de pesquisa aprimora a inovação original (CAPPELLI, CZARNITZKI, KRAFT, 2014).

Em pesquisa com a participação de 137 pequenas e médias empresas de fabricação chinesas, explorando-se empiricamente as relações entre as diferentes redes de cooperação e o desempenho de inovação, concluiu-se que existem relações positivas significativas entre cooperação entre empresas, cooperação com instituições intermediárias, cooperação com organizações de pesquisa e desempenho de inovação das pequenas e médias empresas, das quais a cooperação entre empresas tem o impacto positivo mais significativo no desempenho de inovação. $O$ resul- tado revela ainda que a ligação e a cooperação com agências governamentais não demonstra nenhum impacto significativo no desempenho da inovação. Além disso, essas descobertas confirmam que a cooperação vertical e horizontal com clientes, fornecedores e outras empresas desempenha um papel destacado no processo de inovação das empresas do que a cooperação horizontal com instituições de pesquisa, universidades ou faculdades e agências governamentais (ZENG, 2009)

Outro inquérito ligado à Inovação da Comunidade Francesa (CEI) indica que 14\% das empresas colaboradoras de $P \& D$ tiveram que abandonar ou atrasar seus projetos de inovação devido a dificuldades em suas parcerias, resultado que denominamos "falhas de cooperação". Controlando a seleção de amostras na decisão de cooperação, as estimativas mostraram que as empresas que colaboram com concorrentes e organizações públicas de pesquisa (PRO), especialmente quando são estrangeiras, são mais propensas a atrasar ou parar um projeto de inovação devido às dificuldades encontradas em suas parcerias de P \& D. Mais surpreendentemente, as empresas que colaboram com seus fornecedores também enfrentam um maior risco de "falhas de cooperação". Pelo menos para as PROs, as empresas podem reduzir o risco de "falhas de cooperação" por meio de experiências anteriores em parcerias. As empresas maiores e as subsidiárias do grupo são menos propensas a enfrentar "falhas de cooperação" (LHUILLERY, 2009).

Uma estratégia organizada de Pesquisa e Desenvolvimento permite que a empresa participe de grupos de pesquisa e centros de desenvolvimento tecnológicos acessando novos conhecimentos e habilitando a força de trabalho a indicarem as melhores tecnologias a serem introduzidas. É fundamental uma estratégia para inventariar as boas práticas de operação e as tecnologias existentes, no intuito de sistematizá-las a partir de 
manuais e materiais de treinamento. A partir do momento em que as tecnologias da companhia já foram mapeadas e sistematizadas, é possível comercializá-las a outras empresas de saneamento. A rentabilização desses ativos intangíveis só é possível a partir do desenvolvimento de uma política institucional de registro e proteção da propriedade industrial e intelectual (ABES, 2013).

\section{CONCLUSÃO}

Salientando-se que tanto o objetivo geral como o objetivo secundário foi alcançado por este trabalho de pesquisa, tem-se que as principais relações de parceria em cooperação identificadas nesta pesquisa apontam para fornecedores e universidades corroborando como trabalho de Beuren, Floriani e Hein (2014). Por outro lado, a baixa importância atribuída a clientes e consumidores pelos respondentes foi contrária aos trabalhos de Cappelli, Czarnitzki, Kraft (2014) e Zeng (2009), que apontam uma grande relevância para esses parceiros, positivando a hipótese proposta.

O primeiro aspecto ainda no levantamento bibliográfico foi a dificuldade de obtenção de artigos sobre o tema específico. Os artigos da área temática em questão são predominantemente estudos de caso acerca de implantações de inovações nas empresas do setor, não contribuindo para uma visão generalizante do setor.

Outro aspecto relevante é o fato de que os resultados encontrados sobre cooperação para inovação foram provenientes de artigos elaborados sob o contexto de outros setores. Há necessidade de relembrar nesse ponto a singularidade do setor de saneamento, com as questões de monopólio natural, regulação, capital público, todos os fatores inibidores à inovação.

A baixa adesão à participação na pesquisa pode ser uma indicação para estudos futuros. Os contatos foram diretamente feitos junto às empresas por meio dos canais de comunicação disponibilizados nos sites. Mesmo após a identificação dos 12 respondentes das empresas das 21 empresas constatadas da amostra apenas 5 respondentes contribuíram.

A utilização do questionário da PINTEC como referência para obtenção das informações junto às empresas participantes mostrou-se acertada. 0 questionário validado por sua longa data de utilização tornou desnecessária a aplicação de um pré-teste.

Fica como proposta para pesquisas futuras ampliar a amostra de empresas pesquisadas, envolvendo um maior número de gerentes, por meio de uma abordagem quantitativa, com o objetivo de esclarecer questões que não foram elucidadas na pesquisa qualitativa. Este trabalho é apenas o início de uma abordagem acerca de um universo pouco explorado. A demanda de uma continuada rotina de atividades de pesquisa, desenvolvimento e inovação das organizações do setor de saneamento brasileiro trará luz ao tema.

\section{CONTRIBUIÇÃO DOS AUTORES}

Todos os autores contribuíram de forma igualitária.

\section{REFERÊNCIAS}

ABES. Associação Brasileira de Engenharia Sanitária e Ambiental. Prêmio Nacional da Qualidade - 2016. Disponível em: http:// abes-dn.org.br. Acesso em: 15 Mai. 2017.

ANDREASSI, T. Ações internas voltadas ao fomento da inovação: as empresas também devem fazer sua "lição de casa". Cadernos EBAPE. BR, v. 3, n. SPE, p. 01-10, 2005. https://doi.org/10.1590/ S1679-39512005000500011

BARBOZA, R. A. B.; FONSECA, S. A.; RAMALHEIRO, G. C. F. Inovação em micro e pequenas empresas por meio do serviço brasileiro de respostas técnicas. RAl: revista de administração e inovação, v. 12, n. 3, p. 329-349, 2015. https://doi.org/10.11606/rai. v12i3.101225

BEUREN, I. M.; FLORIANI, R.; HEIN, N. Indicadores de inovação nas empresas de construção civil de Santa Catarina que aderiram ao programa brasileiro de qualidade e produtividade no habitat (PB- 
QP-H). Perspectivas em Gestão \& Conhecimento, v. 4, n. 1, p. 161-178, 2014. https://periodicos.ufpb.br/ojs2/index.php/pgc/ article/view/16858. ISSN: 2236-417X

BNDES. Banco Nacional de Desenvolvimento. Perspectivas do investimento 2015-2018 e panoramas setoriais. 2015. Disponível em: www.bndes.gov.br/bibliotecadigital Acesso em: 12 jul. 2016, $175 p$.

BRAGA, K. S. Aspectos relevantes para a seleção de metodologia adequada à pesquisa social em Ciência da Informação. Métodos para a pesquisa em ciência da informação. Brasília: Thesaurus, p. 17-38, 2007.

CAPPELLI, R.; CZARNITZKI, D.; KRAFT, K. Sources of spillovers for imitation and innovation. Research Policy, v. 43, n. 1, p. 115-120, 2014. https://doi.org/10.1016/j.respol.2013.07.016

CASSIMAN, B.; VEUGELERS, R. In search of complementarity in innovation strategy: Internal R\&D and external knowledge acquisition. Management science, v. 52, n. 1, p. 68-82, 2006. https://doi. org/10.1287/mnsc. 1050.0470

CENTURIÓN, W. C.; PAIVA J., F. G.; CORREIA NETO, J. S.; LUCENA, R. L. O processo de inovação tecnológica de empresas fornecedoras associadas à rede Petrogas/SE. RAI: revista de administração e inovação, v. 12, n. 1, p. 24, 2015. https://doi.org/10.11606/rai. v12i1.100312

CHESBROUGH, H. Open Innovation: The New Imperative for Creating and Profiting from Technology, Harvard Business School Press, Boston, MA. 2003.

CHESBROUGH, H., VANHAVERBEKE, W., West, J. Open Innovation: Researching a New Paradigm. USA: Oxford University Press. 2006.

$\mathrm{CNI}$ - Confederação Nacional das Indústrias. Pesquisa de demanda por informação tecnológica pelo setor produtivo. 2014. 11p.

GAVA, E.; ZILBER, M. A. Inovação aberta no setor de saneamento básico no Estado de São Paulo, III SINGEP, 2014, 14 p.

GIL, A. C. Métodos e técnicas de pesquisa social - 6. ed. São Paulo: Atlas, 2008, 200 p.

GOPALAKRISHNAN, S.; DAMANPOUR, F. A review of innovation research in economics, sociology and technology management. Omega, v. 25, n. 1, p. 15-28, 1997. https://doi.org/10.1016/ S0305-0483(96)00043-6

GRIMPE, C.; HUSSINGER, K.. Formal and informal knowledge and technology transfer from academia to industry: Complementarity effects and innovation performance. Industry and innovation, $v$. 20, n. 8, p. 683-700, 2013. https://doi.org/10.1080/13662716.2 013.856620

IBGE - INSTITUTO BRASILEIRO DE GEOGRAFIA E ESTATÍSTICA. Pesquisa de inovação tecnológica. IBGE, 2011.
IBGE - INSTITUTO BRASILEIRO DE GEOGRAFIA E ESTATÍSTICA. Pesquisa de inovação tecnológica. IBGE, 2014.

LEMOS, C. Inovação na era do conhecimento. In: LASTRES, H. M. M;. ALBAGLI, S. (Orgs.). Informação e globalização na era do conhecimento. Rio de Janeiro : Campus, 1999. p. 122-144.

LHUILLERY, S.; PFISTER, E. R\&D cooperation and failures in innovation projects: Empirical evidence from French CIS data. Research Policy, v. 38, n. 1, p. 45-57, 2009. https://doi.org/10.1016/j.respol.2008.09.002

MARTIN, A. R.; TORKOMIAN, A. L. V. A atividade de P\&D na empresa: o caso da indústria petroquímica. Polímeros: Ciência e Tecnologia, v. 11, n. 2, p. E4-E9, 2001. https://doi.org/10.1590/ S0104-14282001000200003

MATTOS, J. F.; STOFFEL, H. R.; TEIXEIRA, R. A. Mobilização empresarial pela inovação: cartilha gestão da inovação. Brasília: Confederação Nacional da Indústria, 2010. 47p.

MCGUIRK, H.; LENIHAN, H.; HART, M. Measuring the impact of innovative human capital on small firms' propensity to innovate. Research Policy, v. 44, n. 4, p. 965-976, 2015. https://doi.org/10.1016/j.respol.2014.11.008

MINAYO, M. C. S.; SANCHES, O. Quantitativo-qualitativo: oposição ou complementaridade. Cadernos de saúde pública, v. 9, n. 3, p. 239-262, 1993. http://dx.doi.org/10.1590/S0102$311 \times 1993000300002$

OCDE. Manual de Oslo: Diretrizes para coleta e interpretação de dados sobre inovação. $3^{\mathrm{a}}$ ed. FINEP, 2005. $184 \mathrm{p}$.

O'SULLIVAN, D.; DOOLEY, L. Applying innovation. Califórnia: Sage publications, $1^{\mathrm{a}}$ ed., 2008, 238p.

PAREDES, B. J. B.; SANTANA, G. A.; CUNHA, T. N.; AQUINO, J. T. Uma análise intrassetorial e intersetorial do grau de inovação de empresas de pequeno porte do estado de Pernambuco. RAl: revista de administração e inovação, v. 12, n. 4, p. 140-161, 2015. http:// www.periodicos.usp.br/rai/article/view/101888. ISSN: 2515-8961

PAULA, H. C.; STARLING, D. B.; NASCIMENTO, J. F.; BARBOSA, F. V. Mensuração da inovação em empresas de base tecnológica. RAl: revista de administração e inovação, v. 12, n. 4, p. 232-253, 2015. https://doi.org/10.11606/rai.v12i4.102277

SABESP - Pesquisa, Desenvolvimento e Inovação: a nova estratégia da Sabesp - 2009. Disponível em: http://www.fapesp.br/ pdf/sabesp/gesner.pdf. Acesso em: 15 Mai. 2017.

SEREIA, V. J.; STAL, E.; CÂMARA, M. R. G. Fatores determinantes da inovação nas empresas agroindustriais de carne. Nova Economia, v. 25 , n. 3, p. 647-672, 2015. http://dx.doi.org/10.1590/0103$6351 / 2344$

SNIS, Sistema Nacional de Informações sobre Saneamento. Diagnóstico dos Serviços de Água e Esgotos - 2015. Brasília: SNSA/ MCIDADES, 2017. 212p. 
TEZA, P.; MIGUEZ, V. B.; FERNANDES, R. F.; DANDOLINI, G. A.; SOU$Z A$, J. A. Ideias para a inovação: um mapeamento sistemático da literatura. Gestão \& Produção, v. 23, n. 1, p. 60-83, 2016. http:// dx.doi.org/10.1590/0104-530X1454-14

TIDD, J.; BESSANT, J. Gestão da inovação-5. Porto Alegre:Bookman Editora, 2015, 633p.

TIGRE, P. B. Gestão da inovação. Rio de Janeiro: Elselvier, 2006, 300p.

VALOR - Ranking 1000 da Revista Valor 2016 Disponível em: http://www.valor.com.br/empresas/2801254/ranking-das-1000-maiores. Acesso em: 01/nov/ 2016.

VEUGELERS, R.. Internal R \& D expenditures and external technology sourcing. Research policy, v. 26, n. 3, p. 303-315, 1997. https://doi.org/10.1016/S0048-7333(97)00019-X

VEUGELERS, R.; CASSIMAN, B. R\&D cooperation between firms and universities. Some empirical evidence from Belgian manufacturing. International Journal of Industrial Organization, v. 23, n. 5, p. 355-379, 2005.
VILLANI, E.; RASMUSSEN, E.; GRIMALDI, R. How intermediary organizations facilitate university-industry technology transfer: A proximity approach. Technological Forecasting and Social Change, v. 114, p. 86-102, 2017. https://doi.org/10.1016/j.techfore.2016.06.004

ZENG, S. X.; XIE, X. M.; TAM, C. M. Relationship between cooperation networks and innovation performance of SMEs. Technovation, v. 30, n. 3, p. 181-194, 2010. https://doi.org/10.1016/j. technovation.2009.08.003

ZHANG, J. e XU, Y. Technological innovation surveys in six provinces of China and main results. In: OCDE Seminar, 26-28 November, 1998. Anais...

WEST, J.; BOGERS, M. Leveraging external sources of innovation: a review of research on open innovation. Journal of Product Innovation Management, v. 31, n. 4, p. 814-831, 2014.

YIN, R. K. Estudo de caso - planejamento e métodos. (2Ed.). Porto Alegre: Bookman. 2001. 